\title{
THE NEMATOCYST EXTRACT OF HYDRA ATTENUATA CAUSES SINGLE CHANNEL EVENTS IN LIPID BILAYERS
}

\author{
Jürgen Weber, Theo Schưrholz and Eberhard NeUmanN \\ Department of Physical and Biophysical Chemistry, Faculty of Chemistry, University of Bielefeld, P.O. Box \\ 8640, D-4800 Bielefeld 1, F.R.G.
}

(Accepted for publication 15 August 1989)

\begin{abstract}
J. Weber, T. Schürholz and E. NeumanN. The nematocyst extract of $H y d r a$ attenuata causes single channel events in lipid bilayers. Toxicon, 28, 403-409, 1990.- The nematocyst extract of Hydra attenuata causes single conductance events in reconstituted planar lipid membranes as well as in inside-out patches derived from liposomes. The smallest single channel conductance level of the toxins is $110 \mathrm{pS}$. The conductance levels increase stepwise with time up to $2000 \mathrm{pS}$. These large conductance jumps indicate channel cooperativity. If the membrane-voltage is changed from positive to negative values, the single channel events become undefined and noisy, indicating major reorganizations of the proteins which form the channels. The molecular properties of the ionophoric component(s) of the nematocyst extract may help explain the observed macroscopic effects, such as hemolysis of human erythrocytes, after addition of the nematocyst extract.
\end{abstract}

\section{INTRODUCTION}

NEMATOCYSTS are specialized organelles found exclusively in the fishing tentacles of the coelenterata. One of the non-marine coelenterata is Hydra, a freshwater polyp. When triggered by prey or predators, the nematocysts eject their contents within msec, thereby paralyzing and finally killing the target organisms (TARDENT and HoLSTEIN, 1982; HoLSTEIN and TARDENT, 1984).

The $H y d r a$ nematocysts contain large amounts of the divalent ions $\mathrm{Ca}^{2+}$ and $\mathrm{Mg}^{2+}$. The divalent ion concentration inside the capsule is about 1 mole per liter (WEBER et al., 1985). Approximately $75 \%$ of the nematocyst dry weight consists of soluble proteins; $80 \%$ of the protein weight is of low molecular mass $\left(M_{r}<30,000\right)$ and highly anionic, presumably serving as binding sites for $\mathrm{Ca}^{2+} / \mathrm{Mg}^{2+}$. The other $20 \%$ includes 30 different proteins, among them toxins and enzymes, but there is very low protease and no chitinase activity detectable. The extract displays a rather low divalent cation-dependent phospholipase activity on egg yolk (WEBER et al., 1987). The nematocysts' soluble components are lethal for Drosophila flies $\left(\mathrm{LD}_{\mathbf{5}}=2 \mathrm{ng} / \mathrm{fly}\right)$. Injection of these soluble components or a direct tentacle contact lead to the contraction of Drosophila melanogaster larvae. Depending on the amount injected, the larvae are partially or totally paralyzed. Unidirectional, wave-like contraction of individual muscles can be observed after injection. The number and speed 
of these contractions gradually decrease in the course of time. The extract is hemolytic to human erythrocytes in the absence of divalent cations (KLUG et al., 1985).

The toxins of related animals such as those of Chrysaora or Chironex, change the ionic permeability of biological membranes and of lipid bilayer membranes (BURNETT and CALton, 1977). The addition of $5 \mathrm{mg}$ sea nettle lethal factor from Chrysaora to black lipid membranes (BLM) lead initially to a conductance event of $31 \mathrm{pS}$ at $100 \mathrm{mM} \mathrm{NaCl}$. The conductance increases to higher multiples of $31 \mathrm{pS}$. Substitution of $\mathrm{NaCl}$ by $50 \mathrm{mM} \mathrm{CaCl}$ or $\mathrm{MgCl}_{2}$ abolishes the conductance events (CoBBS et al., 1983). The application of Chrysaora toxin to the nodal membrane of Rana, causes single conductance events of $760 \pm 40 \mathrm{pS}$ (Dubois et al., 1983). SHRYOCK and BiANCHI (1983) measured a conductance of $185 \mathrm{pS}$ for a single channel in BLM (Ringers solution at an ionic strength of $126 \mathrm{mM}$ ). A single conductance level of $30 \mathrm{pS}$ is found after addition of the toxins from Chironex to BLM. At higher toxin concentrations ( $3 \mathrm{mg}$ protein), which are usually lethal, the conductance levels increase in multiples of $30 \mathrm{pS}$ and no $\mathrm{Na}^{+} / \mathrm{K}^{+}$selectivity is detected (OLson et al., 1984). The toxins of Stoichactis applied to BLM (500 mM KCl) cause conductance levels which are different for a voltage of $+100 \mathrm{mV}(180 \mathrm{pS})$ and $-100 \mathrm{mV}$ (100 pS) (MICHAELS, 1979). VARANDA and FINKELSTEIN (1980) report a conductance value of $200 \mathrm{pS}$ at $100 \mathrm{mM} \mathrm{KCl}$ for the same toxin $(100 \mathrm{mM} \mathrm{KCl})$.

The present study shows that the nematocyst extract contains at least one ionophoric component which drastically changes the cation permeability of the target membranes.

\section{MATERIALS AND METHODS}

The nematocyst extract was a gift from Dr J. WEBER (Zürich), who developed a new method for isolating undischarged nematocysts of Hydra (WEBER et al., 1987). Lipid bilayer vesicles were prepared from $20 \mathrm{mg}$ acetone-washed soybean phospholipids (Avanti, 20\% PC) and $1.5 \mathrm{mg}$ cholesterol (Sigma) dissolved in chloroform. The vesicles were formed after adding buffer to the nitrogen-dried lipid/cholesterol film in the round bottom flask. For the planar bilayer experiments, $20 \mathrm{ml}$ buffer $\mathrm{A}\left(300 \mathrm{mM} \mathrm{NaCl}, \mathrm{KCl}, \mathrm{NH}_{4} \mathrm{Cl}\right.$ or Tris(hydroxymethyl)-aminomethan-hydrochloride (Tris- $\mathrm{HCl}$ ), $1 \mathrm{mM} \mathrm{CaCl}, 10 \mathrm{mM} \mathrm{N}$-2-hydroxyethylpiperazine-N-2-ethanesulfonic acid (Hepes), pH 7) was added. In the patch-clamp experiments, $10 \mathrm{ml}$ buffer $\mathrm{B}$ ( $300 \mathrm{mM} \mathrm{NaCl}$ or $\mathrm{KCl}$, $1 \mathrm{mM} \mathrm{CaCl}, 10 \mathrm{mM}$ Hepes, $\mathrm{pH}$ 7) was used. Glass beads increase vesicle formation during agitation of the bottle. The protein content of the nematocyst extract used in liposomes was $10 \mathrm{ng}$ protein/mg lipid.

The planar bilayer was derived from vesicle suspensions at $20^{\circ} \mathrm{C}$ using the septum-supported, vesicle-derived bilayer (SVB) technique (SCHINDLER, 1980; SCHÜRHOLZ and SCHINDLER, 1983). The nematocyst extract was added either together with the buffer to the dried lipid film in a round bottom flask, or to the aqueous phase of the compartment (cis-side) of the planar bilayer cell, after the vesicle suspension was replaced by buffer solution.

The potential difference across the planar bilayer was controlled by a voltage clamp circuit. The solution on the trans-side was maintained at zero potential. In both methods (patch-clamp, SVB) $\mathrm{Ag} / \mathrm{AgCl}$ electrodes were used; positive membrane current corresponds to cation flow from the cis-side (toxin application) to the trans-side of the membrane.

For the liposome patch-clamp experiments (HAmLl et al., 1981) $10 \mathrm{ml}$ of the vesicle-suspension was added to the bottom of a culture dish ( $20 \mathrm{~mm}$ diameter) and then filled with buffer B (as described above). After a seal of $>10$ GOhm had formed, the pipette was withdrawn from the vesicle and exposed to air, to ensure the formation of an inside-out patch (TANK et al., 1982). The diameter of the vesicles used for patching was $>5 \mathrm{~mm}$. Positive holding voltage was defined as a positive potential (cation-flow out) on the pipette interior of an EPC7 amplifier (List, Germany). The output signals were filtered at $3 \mathrm{kHz}$ in both methods and recorded on a video tape recorder after digitization by a pulse code modulator, modified to accept DC signals (PCM 501, Sony).

\section{RESULTS}

The nematocysts extract of Hydra induced ion channels when incorporated into vesicle-derived planar bilayers and in inside-out patches of liposomes. At an extract concentration of $10 \mathrm{ng}$ protein/mg lipid, conductance events were identified in about every fifth membrane patch. The area of the patch was about $0.2 \mu \mathrm{m}^{2}$. 


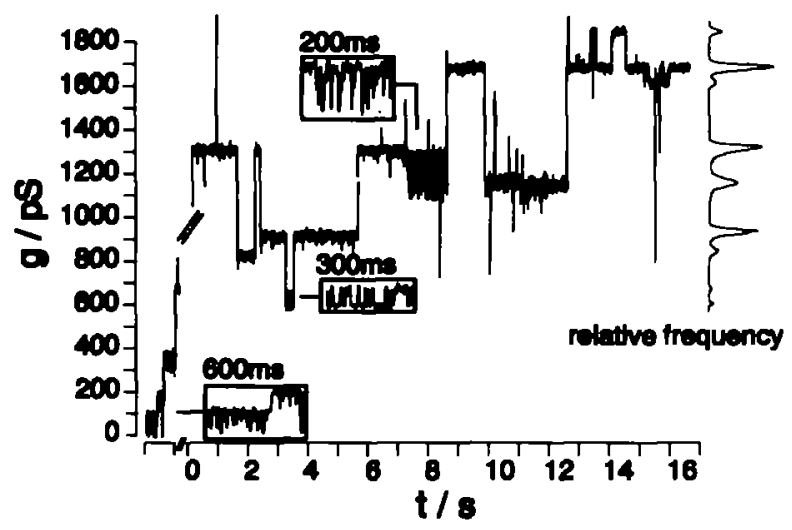

Fig. 1. Single CHANNEl CONDUCTANCE (g) EVENTS CAUSED by tHE NEMATOCYST EXTRACT of $H y d r a$ attenuata IN A PLANAR LIPID BILAYER, DISPLAYED ON THE TIME $(t)$ SCALE.

Buffer in both the cis and the trans compartments of the bilayer sample cell; $0.3 \mathrm{M} \mathrm{NaCl}, 1 \mathrm{mM}$

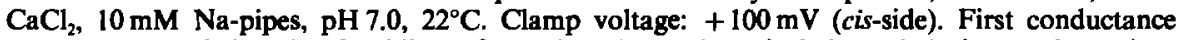
events are recorded $5 \mathrm{~min}$ after bilayer formation. At $t>0$ : typical channel closings and openings on relatively high conductance levels. Inserts: $200 \mathrm{msec}, 300 \mathrm{msec}$ and $600 \mathrm{msec}$ expansions, respectively, of channel flickering. Amplitude histogram (relative frequency of conductance levels) of the time interval $0-17 \mathrm{sec}$.

When the extract was added to a vesicle-containing compartment of the planar bilayer, cell channel activity was not detected in the first $20 \mathrm{~min}$ after addition. The addition of the extract to the aqueous phase (after vesicle removal) led to the conductance events after 5-15 min. Interestingly, the time until channels appeared was not shorter when the planar bilayer is formed from vesicles preequilibrated with the toxin extract (time measured from membrane formation). At $\left[\mathrm{Ca}^{2+}\right]=10 \mathrm{mM}$, the time until channels appeared was 10-30 min compared with 5-15 min for solutions without $\mathrm{Ca}^{2+}$.

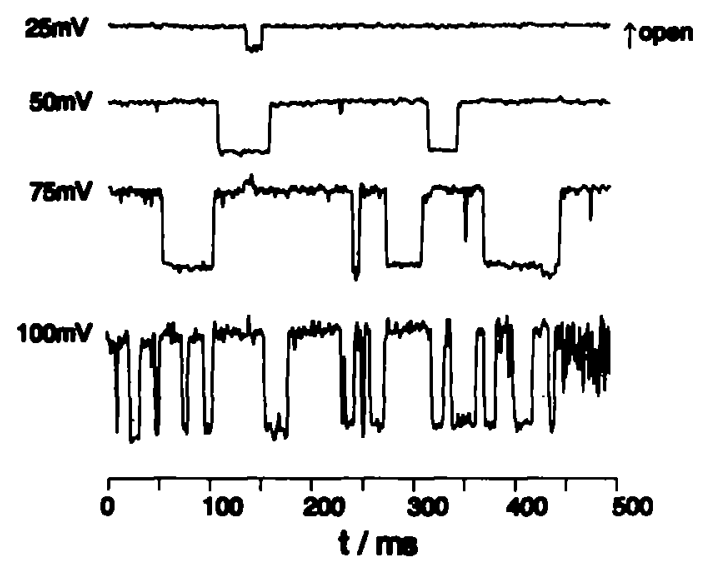

Fig. 2. ChaNNEL tRaCES OF IONOPHORIC COMPONENT(S) OF THE NEMATOCYST EXTRACt INCORPOR-

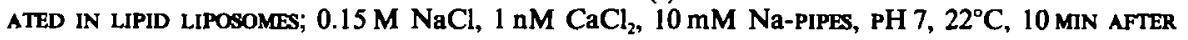
THE FIRST EVENTS OCCURRED.

The most frequent conductance event is $240 \mathrm{pS}$; opening and closing on top of a $1000 \mathrm{pS}$ conductance level. Channel activity is recorded in the inside-out patch clamp mode at $+25,50,75$ and $+100 \mathrm{mV}$ (pipette inside positive). 


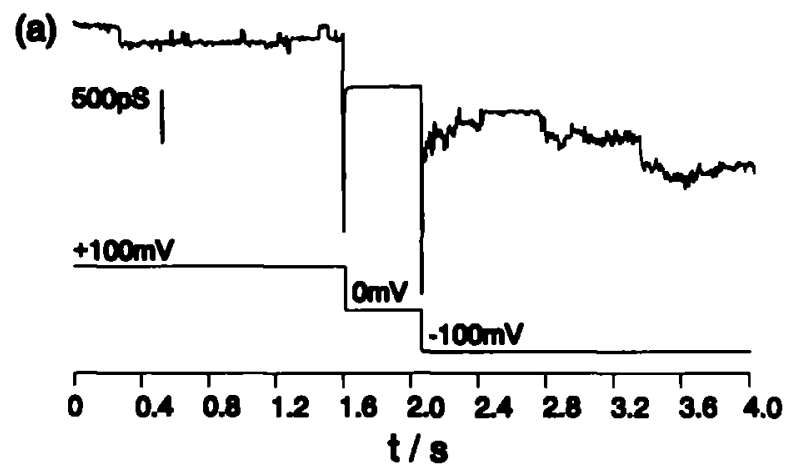

(b)

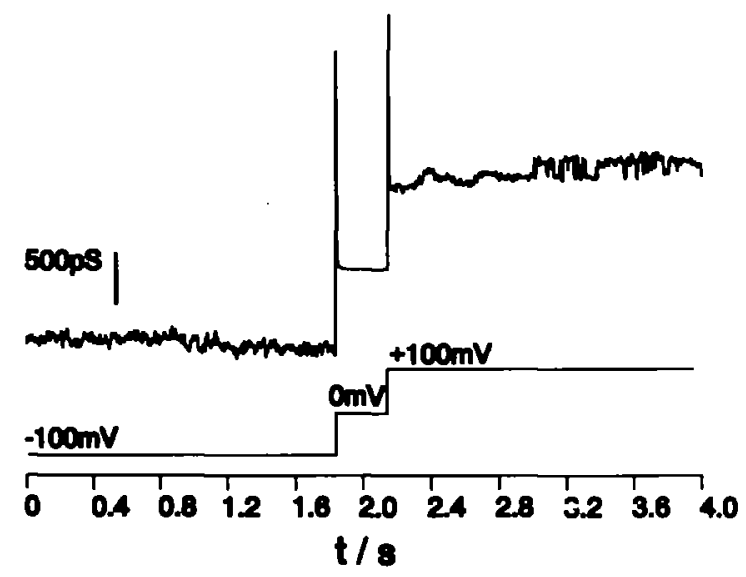

Fig. 3. Change in THE ChanNel PATtERn OF THE lONOPHORIC COMPONENT(s) OF THE EXTRACT IN A PLANAR LIPID BILAYER AFTER CHANGING THE VOLTAGE POLARITY.

(a) From $+100 \mathrm{mV}$ (cis-side, toxin addition) to $-100 \mathrm{mV} ; 0.3 \mathrm{~N} \mathrm{NaCl}, 1 \mathrm{mM} \mathrm{CaCl}, 10 \mathrm{mM} \mathrm{Na}$ pipes, $\mathrm{pH} 7.0,22^{\circ} \mathrm{C}$. (b) Return to $+100 \mathrm{mV}$ (reappearance of discrete channel pattern).

A typical trace of Hydra extract-induced conductance events is shown in Fig. 1. Two channel properties are readily obvious: switching between different long-lasting conductance levels as well as a frequent switching between apparently only two states (flickering; see the inserts in Fig. 1 and Fig. 2). The flickering events can last for about $5 \mathrm{~min}$ and occur over the whole range (about $2000 \mathrm{pS}$ ) of the longer lasting (open times $>>$ open times of flickering) conductance levels.

The smallest channel conductance is $110 \mathrm{pS} \pm 20 \mathrm{pS}$ at $300 \mathrm{mM} \mathrm{NaCl}$ or $\mathrm{KCl}$. The most abundant channel amplitude was in the range of $220 \pm 25 \mathrm{pS}$. After extract application, only small conductance steps are seen; with time, gradually larger steps occurred, going up to a level of, e.g. $2000 \mathrm{pS}$. The ion channels, once formed, are open most of the time. Therefore, when the mean conductance has reached a larger constant value, the smaller conductance changes, especially the flickering, appear as single channels on top of a larger constant conductance level.

In the range of 0 to $+100 \mathrm{mV}$ the channels show an ohmic current-voltage behaviour (Fig. 2). When the voltage was reversed to a negative value (pipette interior), the clear channel events vanished within $1 \mathrm{sec}$ and turned into undefined conductance changes. 
TABLE 1. OPEN $\left(\tau_{a}\right)$ AND CLOSED $\left(\tau_{c}\right)$ TMMES, RESPECTIVELY, OF FLICKERING AT VARIOUS HOLDING VOLTAGES $\left(V_{h}\right)$

\begin{tabular}{ccc}
\hline $\begin{array}{c}\mathrm{V}_{h} \\
(\mathrm{mV})\end{array}$ & $\begin{array}{c}\tau_{o} \\
(\mathrm{msec})\end{array}$ & $\begin{array}{c}\tau_{c} \\
(\mathrm{msec})\end{array}$ \\
\hline 50 & $170 \pm 35^{*}$ & $19 \pm 4$ \\
75 & $30 \pm 5$ & $13 \pm 3$ \\
100 & $19 \pm 4$ & $6 \pm 2$ \\
\hline
\end{tabular}

*The open and closed times are mean values \pm S.D. of 6 traces. The values were computed for each holding potential and each trace from at least 200 single channel events.

After returning to positive voltage, the clear and distinct channels were again seen within $1 \mathrm{sec}$ (Fig. 3).

The frequency of flickering increased with voltage (Fig. 2). In Table 1 the time constants of the open $\left(\tau_{o}\right)$ and the closed state $\left(\tau_{c}\right)$ of a flickering trace are listed as a function of voltage. Between 50 and $100 \mathrm{mV},\left(\tau_{o}\right)$ decreased by a factor of about $10,\left(\tau_{c}\right)$ by a factor of 3. The numerical values of the time constants are derived from fittings of the time open-/ closed time distributions with one exponential-function $\mathrm{y}=A \cdot \mathrm{e}^{-t / \tau}$, where $\tau$ is either the mean open or the mean closed time.

Channel formation was measured in four different $300 \mathrm{mM}$ salt solutions: $\mathrm{NaCl}, \mathrm{KCl}$, $\mathrm{NH}_{4}$ and Tris- $\mathrm{HCl}$ (pH 6.8). The single conductances of the smallest steps are $110 \mathrm{pS}$ $(\mathrm{NaCl}), 110 \mathrm{pS}(\mathrm{KCL}), 130 \mathrm{pS}\left(\mathrm{NH}_{4} \mathrm{Cl}\right)$ and $55 \mathrm{pS}$ (Tris- $\mathrm{HCl}$ ). A similar conductivity profile was attributed to that of a nonselective water filled pore (LEWIs et al., 1983). When $\mathrm{Ca}^{2+}$ was added to the aqueous phases (cis- and trans-side), containing $300 \mathrm{mM} \mathrm{NaCl}$, the conductivity did not change significantly between $\left[\mathrm{Ca}^{2+}\right]=1 \mathrm{mM}$ and $10 \mathrm{mM}$.

\section{DISCUSSION}

A characteristic feature of a variety of ionophoric cell toxins is the spontaneous incorporation into membranes from the aqueous phase. The ionophoric component(s) of the nematocyst extract of Hydra attenuata also go into the lipid-membranes and cause ion channel formation. Compared with other pore forming molecules like gramicidin and alamethicin, the $H y d r a$ nematocyst extract needs a relatively long incubation time until channels can be recorded electrically. When planar bilayers are formed from vesicles containing gramicidin, channels can be recorded instantaneously after bilayer formation (unpublished results).

The ionophoric component of the nematocyst extract of Hydra needs about 15 min to form channels and time is the same when the vesicles used to form planar bilayers are incubated with the extract or when the extract is added to the preformed planar lipid bilayer. Therefore, it seems that the time-consuming step is not the mere incorporation of the ionophoric component(s). Rather, the data suggest that the formation of the channels involves major reorganizations of the ionophoric molecules on or within the bilayer.

In the presence of $\mathrm{Ca}^{2+}$ the incubation time increased. If the channel formation depends on the diffusion-controlled aggregation of ionophoric molecules similar to that of alamethicin (SCHWARZ and SAVKO, 1982) the effect of $\mathrm{CA}^{2+}$ can be rationalized in terms of an increase in lateral pressure of the bilayer and the concomitant decrease of the diffusion 
coefficient of the toxins. It therefore appears that the channels are caused by aggregation of several ionophoric molecules as is the case with alamethicin. The aggregation model is also supported by the size distribution of the channels. The stepwise increase in the conductance levels is different from the cooperative opening of clusters of several single channel proteins such as the nicotinic acetylcholine receptor (SCHINDLER et al., 1984; ScHÜRHOLz et al., 1988). The ionophoric component forms pores up to $2000 \mathrm{pS}$, which are open most of the time. This property can disturb the transmembrane-potential by facilitating the flux of ions and water across the membrane. The observed macroscopic effects of the nematocyst extract (KLUG et al., 1985) may be attributed to the properties of the ionophoric component characterized here.

After reversing the voltage polarity, the channel behavior changes within one sec. Such a small time constant suggests rearrangements of larger aggregates rather than a reorientation of a single molecule. The time constants of the open and closed states decrease with increasing voltage thereby increasing the flickering frequency. When the time constant of the open state decreased to more than that of the closed state, the probability of the channel being in the open state also decreased. But the shift from $90 \%$ to $75 \%$ open appears too small to account for an obvious functional role of this channel behaviour; the flickering is only a small change on top of a larger constant conductance.

It is likely that in the nematocysts the ionophoric components are inhibited, perhaps complexed with inhibitors so that there is no effect on the nematocyst membrane. Since hemolysis of human erythrocytes is inhibited in the presence of $\mathrm{Ca}^{2+}$ and $\mathrm{Mg}^{2+}$ solutions, $\mathrm{Ca}^{2+} / \mathrm{Mg}^{2+}$ binding appears to be involved in the inactivation of the ionophoric component of the extract. In the concentration range of $1-10 \mathrm{mM} \mathrm{Ca}^{2+}$, which does not affect bilayer stability, there is no effect on the channel activity of the reconstituted toxins. Either this concentration range is too small compared with the natural divalent ion concentration (about 1 mole per liter) of the nematocyst or the $\mathrm{Ca}^{2+}$-inhibition effect may be indirect; perhaps a further component of the extract binds $\mathrm{Ca}^{2+}$ and, as a $\mathrm{Ca}^{2+}$ complex, may inhibit the channel-active toxins.

In summary, our channel data suggest the possibility that a microscopic membrane mechanism may be responsible for the dramatic macroscopic effects of the nematocyst extract: hemolysis of erythrocytes or larvae contraction may be caused by the pore formation after incorporation of ionophoric components of the nematocyst extract.

Acknowledgements-We thank Dr J. WEBER, Zürich, for the kind gift of the Hydra toxin. The financial support of the Deutsche Forschungsgemeinschaft, SFB 223, grant D3 to E.N., is gratefully acknowledged.

\section{REFERENCES}

Burnett, J. W. and CAlton, G. J. (1977) The chemistry and toxicology of some venomous pelagic coelenterates. Toxicon 15, 177-196.

Cobes, C. S., Dryzmala, R., Shamoo, A., Calton, G. J. and Burnett, J. W. (1983) Sea nettle (Chrysaora quinquecirrha) lethal factor: effect on black lipid membranes. Toxicon 21, 558-561.

Dubois, J., TANGAY, J. and BurnetT, J. W. (1983) Ionic channels induced by sea nettle toxin in the host membrane. Biophys. J. 42, 199-201.

Hamil, O. P., Marty, A., Neher, E., Sakmann, B. and Sigworth, F. J. (1981) Improved patch-clamp techniques for high-resolution current recording from cells and cell-free membrane patches. Pfügers Arch. $391,85$.

HolsTeIN, Th. and Tardent, P. (1984) An ultrahigh-speed analysis of exocytosis: nematocyst discharge. Science 223, 830-833.

KLUg, M., Werer, J. and TARDENT, P. (1985) Nematocysts of Hydra: biological and biochemical characteristics of their venom. Experientia 41, 784. 
Lewis, C. A. and Stevens, C. F. (1983) Acetylcholine receptor channel ionic selectivity: ions experience an aqueous environment. Proc. Natn. Acad. Sci. U.S.A. 80, 6110-6113.

Michaes, D. W. (1979) Membrane damage by toxin from the sea anemone, Stoichactis helianthus. I. Formation of transmembrane channels in lipid bilayers. Biochim. biophys. Acta 555, 67-78.

Olson, C. E., Pockl, E. E., Calton, G. J. and BuRnett, J. W. (1984) Immunochromatographic purification of a nematocyst toxin from the Cnidaria Chironex fleckeri (sea wasp). Toxicon 22, 733-742.

SCHINDLER, H. (1980a) Formation of planar bilayers from artificial or native membrane vesicles. FEBS Lett. 122 , 77-79.

SCHINILER, H. (1980b) Formation of planar bilayers from artificial or the surface of a liposome solution. Biochim. Biophys. Acta 555, 316-336.

SCHINDler, H., SPIllecke, F. and NeumanN, E. (1984) Different channel properties of acetylcholine receptor monomers and dimers reconstituted in planar membranes. Proc. Natn. Acad. Sci. USA 81, 6222-6226.

SCHÜRHOLZ, T. and SCHINDLER, H. (1983) Formation of lipid-protein bilayers by micropipette guided contact of two monolayers. FEBS Lett. 152, 187-190.

SchUrholz, T., Weber, J. and Neumann, E. (1989) Reconstitution of the Torpedo californica nicotinic acetylcholine receptor into planar lipid bilayers. Bioelectrochem. Bioenerg. 21, 71-81.

Schwarz, G. and SAvko, P. (1982) Structural and dipolar properties of the voltage-dependent pore former alamethicin in octanol/dioxane. Biophys. J. 39, 211-219.

SHR YOCK, J. C. and BianCH, C. P. (1982) Sea nettle (Chrysaora quinquecirrha) nematocyst venom: mechanism of action on muscle. Toxicon 21, 81-95.

TANK, D. W., Miller, C. and WeBb, W. W. (1982) Isolated patch recording from liposomes containing functionally reconstituted chloride channels from Torpedo electroplax. Proc. Natn. Acad. Sci. U.S.A. $79,7749$.

TARDENT, P. and HolsteIN, Th. (1982) Morphology and morphodynamics of the stenotele nematocyst of $H y d r a$ att. Pull. (Hydrozoa, Cnidaria). Cell Tissue Res. 224, 269-290.

VARANDA, W. and FinkelsteIN, A. (1980) Ion and nonelectroyte permeability properties of channels formed in planar bilayer membranes by the cytolytic toxin from the sea anemone, Stoichactis helianthus. J. Membrane Biol. 55, 203-211.

Weber, J., KLUG, M. and TARDENT, P. (1985) Nematocyst of Hydra: isolation and general properties of toxic and other components. Experientia 41, 792.

WEBER. J., KLUG, M. and TARDENT, P. (1987) Some physical and chemical properties of purified nematocysts of Hydra attenuata pall. Comp. Biochem. Physiol. B 88, 855-862. 